\title{
Transverse stent placement for hilar malignant biliary obstruction through an endoscopic ultrasound-guided hepaticogastrostomy route
}

A 70-year-old woman who had undergone endoscopic placement of multiple stents for hilar biliary obstruction due to gallbladder cancer was admitted with cholangitis. In her previous hospitalization, endoscopic ultrasound-guided hepaticogastrostomy (EUS-HGS) had been performed for the bile duct at segment

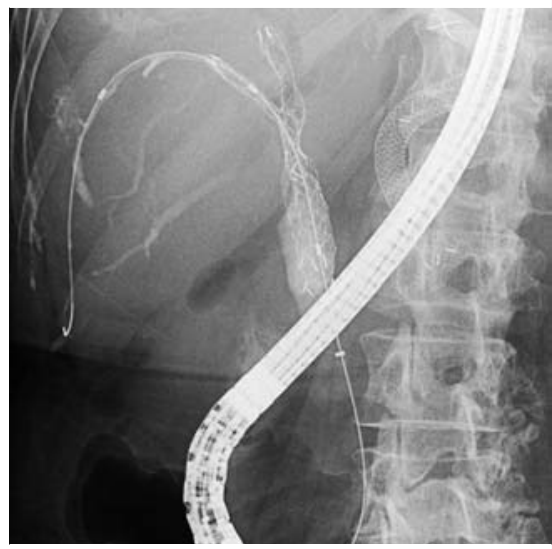

- Fig. 1 Radiographic view showing placement of uncovered metal stents in a partial stent-in-stent fashion following endoscopic ultrasound-guided hepaticogastrostomy.
III (B3) using a partially covered self-expandable metal stent (SEMS; modified Giobor, $10 \times 80 \mathrm{~mm}$; Taewoong Medical Inc., Gimpo, Korea [1]). To manage subsequent episodes of cholangitis, two uncovered SEMSs were placed via the transpapillary route for B7 and B8 in a partial stent-in-stent fashion ( $\mathbf{F i g . 1}$ ). On this admission, endoscopic drainage was scheduled to manage segmental cholangitis in B8.

In the first session, transpapillary biliary drainage of B8 failed as a cannula could not be passed through the mesh wall of the indwelling SEMS ( $\triangleright$ Fig. $\mathbf{2 a}$ ). Therefore, we attempted to access B8 though

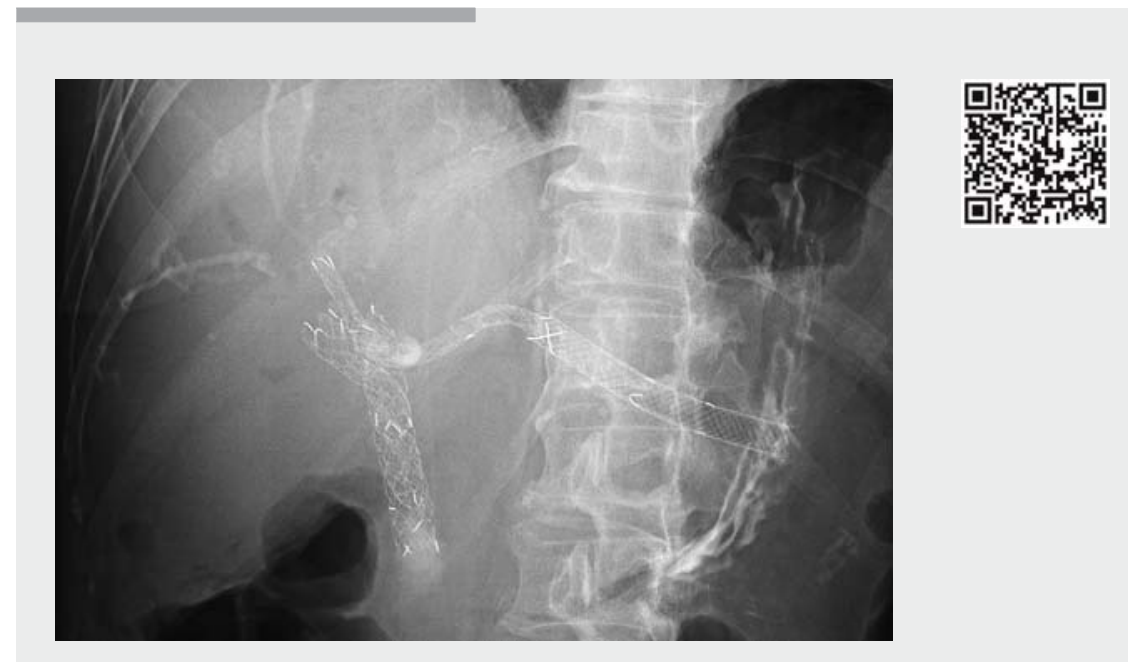

Video 1 Placement of a metal stent bridging a hilar malignant biliary stricture through an indwelling hepaticogastrostomy stent.
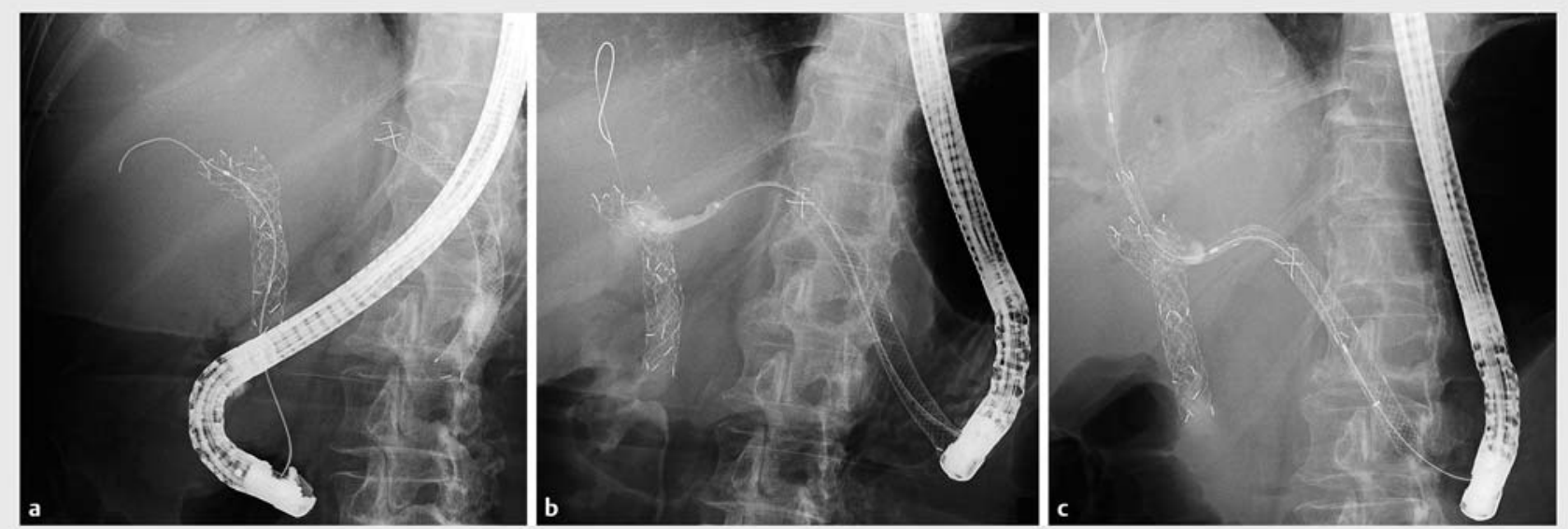

- Fig. 2 Placement of a metal stent bridging a hilar malignant biliary stricture through an indwelling hepaticogastrostomy (HGS) stent after an unsuccessful transpapillary re-intervention. a During the transpapillary approach to B8, a cannula cannot be passed through the mesh wall of the indwelling SEMS. $\mathbf{b}$ Balloon dilation of a mesh interstice of the self-expandable metal stent (SEMS) is performed. $\mathbf{c}$ An uncovered SEMS is placed between B8 and B3 via the EUS-HGS route. 
the EUS-HGS stent. Using a side-viewing duodenoscope, we passed a guidewire into the ventral branch of B8 and dilated the mesh of the SEMS using a balloon catheter ( $\triangleright$ Fig. $\mathbf{2 b}$ ). We then placed a nasobiliary catheter to manage the cholangitis. In the following session, we trimmed the gastric end of the EUS-HGS stent using argon plasma coagulation (ESG-100; Olympus, Tokyo, Japan) to facilitate insertion of the stent [2] and deployed an uncovered SEMS (Niti-S, $10 \times 80 \mathrm{~mm}$; Taewoong Medical Inc.) ( $\triangleright$ Fig. 2c; $\triangleright$ Video 1). There were no procedure-related adverse events.

Endoscopists occasionally face technical difficulties in managing occlusion of SEMSs placed for hilar biliary obstruction. The transpapillary approach is often used for re-intervention for the right-sided biliary system and, recently, the feasibility of EUS-guided hepaticoduodenostomy has been reported $[3,4]$; however, both procedures are technically demanding. Furthermore, EUS-guided access to B8 is often anatomically impossible. Access to the right intrahepatic bile duct via the EUS-HGS route can offer an alternative strategy in this setting [5].

Endoscopy_UCTN_Code_TTT_1AR_2AG

Competing interests

None
The authors

Sachiko Kanai", Tomotaka Saito*, Ryunosuke Hakuta, Yousuke Nakai, Kazuhiko Koike Department of Gastroenterology, Graduate School of Medicine, The University of Tokyo, Tokyo, Japan

\section{Corresponding author}

\section{Yousuke Nakai, MD, PhD}

Department of Gastroenterology, Graduate School of Medicine, The University of Tokyo, 7-3-1 Hongo, Bunkyo-ku, Tokyo 113-8655, Japan

Fax: +81-3-38140021

ynakai-tky@umin.ac.jp

\section{References}

[1] Nakai $\mathrm{Y}$, Isayama $\mathrm{H}$, Yamamoto $\mathrm{N}$ et al. Safety and effectiveness of a long, partially covered metal stent for endoscopic ultrasound-guided hepaticogastrostomy in patients with malignant biliary obstruction. Endoscopy 2016; 48: 1125-1128

[2] Hamada T, Nakai Y, Isayama H et al. Trimming a covered metal stent during hepaticogastrostomy by using argon plasma coagulation. Gastrointest Endosc 2013; 78 : 817

[3] Ogura T, Sano T, Onda S et al. Endoscopic ultrasound-guided biliary drainage for right hepatic bile duct obstruction: novel technical tips. Endoscopy 2015; 47: $72-75$
[4] Park SJ, Choi JH, Park DH et al. Expanding indication: EUS-guided hepaticoduodenostomy for isolated right intrahepatic duct obstruction (with video). Gastrointest Endosc 2013; 78: $374-380$

[5] Prachayakul V, Aswakul P. Endoscopic ultrasound-guided biliary drainage: Bilateral systems drainage via left duct approach. World J Gastroenterol 2015; 21: 10045 - 10048

\section{Bibliography}

Dol https://doi.org/10.1055/a-0889-7329

Published online: 9.5.2019

Endoscopy 2019; 51: E245-E246

(c) Georg Thieme Verlag KG

Stuttgart · New York

ISSN 0013-726X

\section{ENDOSCOPY E-VIDEOS}

https://eref.thieme.de/e-videos

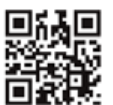

Endoscopy E-Videos is a free access online section, reporting on interesting cases and new techniques in gastroenterological endoscopy. All papers include a high quality video and all contributions are freely accessible online.

This section has its own submission website at

https://mc.manuscriptcentral.com/e-videos

* equal first authors 